${ }^{3}$ International Commiss icn cn Radiological Protection, Publication No. 9 (Pergamon, Oxford, 1966).

t Donth, H. H., and Maushart, R., Health Phys., 12, 106 (1966).

${ }^{5}$ International Commission on Radiological Protection, Publication No. 12 (Pergamon, Oxford, 1969).

\section{Defence of Criteria for the Designation of Persons working with Unsealed Radioactive Substances}

BusH's comments (in the preceding communication) are a welcome development of the proposals in my earlier letter which are intended as a broad administrative guide capable of refinement if more precise levels of activity are to be set.

The maximum activity to be handled at one time would be increased by a factor of 6 if Bush's suggestion (1) is taken. But my original figures have not proved restrictive for most users in the University. Suggestion (2) makes a very important revision of the IFTAH in the case of gaseous and volatile substances and the figures for ${ }^{85} \mathrm{Kr}$ and ${ }^{133} \mathrm{Xe}$ in my letter should be adjusted accordingly.

Bush's suggestion for increasing the maximum turnover in experiments per quarter by a factor of 100 is inferred from the guidance of the ICRP ${ }^{1}$ on the need to monitor individuals for internal contamination when handling gaseous or volatile materials and it would be very helpful if explicit rocommendations could be made on this point. If the values are increased by a factor of 100 , however, the need to provide individual monitoring for external radiation has to be considered because the activities of the sources will be appreciably higher than the levels set by the ICRP ${ }^{1}$ for the introduction of such monitoring.

I am hoping that this correspondence will lead to the eventual inclusion in the appropriate codes of practice of further guidance on the levels at which designation is necessary.

Radiation Protection Service,

D. HuGHes

University of Leeds.

${ }^{1}$ International Commission on Radiological Protection, Publication No. 12 (Pergamon, Oxford, 1969).

\section{Marijuana and Memory}

THE effects of marijuana are not consistent from subject to subject ${ }^{1}$. Any discussion of its effect on human memory (such as refs. 2 and 3 ) must therefore consider whether valid generalizations can be drawn from the subjects who have been examined. One way of minimizing individual differences is to use subjects as their own controls, as is done in the present study which investigates the effects of marijuana on the recall of narrative material.

The subjects were eight men and women aged from 22 to 37 . All but one were college students, and all had used marijuana several times before the experiment. Each was tested singly in two sessions separated by more than a month. In the first session, half of them were given marijuana and half acted as controls; in the second session, the roles were reversed. Those receiving the drug were given two marijuana cigarettes the tetra-hydro cannabinol content of which had not been ascertained. After smoking both, each subject was allowed to relax or read. Five minutes later the experimenter asked the subject whether he felt "high". All subjects answered affirmatively.

The experimenter, who remained in the same room throughout the test, then gave the subject a copy of Bartlett's War of the Ghosts ${ }^{4}$, and told him to read it through twice, at his own speed. When the subject had finished, the story was removed. Fifteen minutes later the experimenter gave the subject a pen and paper and asked him to recall as much of the story as he could accurately remember, using the same words and phrases if possible. When the subject had finished, the session was over. The control subjects were put through the same test without taking marijuana.

The protocols were subjected to King's method of analysis $^{5}$ which involves determining: (1) The total number of words in each subject's version of the story. (2) The number of "content words" with the exclusion of all articles, prepositions, conjunctions, and so on. Content words must have appeared in the original story, but can be misspelt or out of sequence. (3) The number of two word sequences in the recalls which had appeared in the original. (4) The number of correctly recalled four word sequences. (5) The number of "idea units", appearing in the recalls, as defined by a division of the original protocol into such units. Because this task required a certain amount of arbitrary judgement, the estimation was made by three arbiters who did not know the subjects or the conditions of the experiment. Their three scores were averaged to give the idea score for each recall. Table 1 shows the results of the analysis.

Table 1. COMPARISON OF RECALI MATERIAL UNDER MARIJUANA (M) AND IS

\begin{tabular}{|c|c|c|c|c|c|c|c|c|c|c|}
\hline \multirow{3}{*}{ Subject } & & & & & & & \multirow{2}{*}{\multicolumn{2}{|c|}{$\begin{array}{c}\text { Four } \\
\text { word } \\
\text { sequences }\end{array}$}} & \multirow{2}{*}{\multicolumn{2}{|c|}{$\begin{array}{l}\text { No. of } \\
\text { idea } \\
\text { units }\end{array}$}} \\
\hline & \multicolumn{2}{|c|}{$\begin{array}{l}\text { Total } \\
\text { words }\end{array}$} & \multicolumn{2}{|c|}{$\begin{array}{l}\text { Identical } \\
\text { content } \\
\text { words }\end{array}$} & \multicolumn{2}{|c|}{$\begin{array}{l}\text { Two } \\
\text { word }\end{array}$} & & & & \\
\hline & $\mathbf{C}$ & M & $\mathbf{C}$ & $\mathbf{M}$ & & $\mathbf{M}$ & $\mathrm{C}$ & $M$ & C & $\mathbf{M}$ \\
\hline $\begin{array}{l}\mathbf{S}_{\mathbf{z}} \\
\mathbf{S}_{\mathbf{z}} \\
\mathbf{S}_{\mathbf{3}} \\
\mathbf{S}_{\mathbf{4}} \\
\mathbf{S}_{\mathbf{5}} \\
\mathbf{S}_{\mathbf{8}} \\
\mathbf{S}_{\mathbf{z}} \\
\mathbf{S}_{\mathbf{B}}\end{array}$ & $\begin{array}{r}227 \\
267 \\
234 \\
55 \\
170 \\
265 \\
215 \\
177 \\
1,610\end{array}$ & $\begin{array}{r}214 \\
256 \\
155 \\
45 \\
159 \\
221 \\
197 \\
204 \\
1,451\end{array}$ & $\begin{array}{r}66 \\
67 \\
61 \\
15 \\
42 \\
73 \\
63 \\
68 \\
455\end{array}$ & $\begin{array}{r}\mathbf{6 6} \\
59 \\
27 \\
12 \\
\mathbf{3 0} \\
47 \\
51 \\
53 \\
\mathbf{3 4 5}\end{array}$ & $\begin{array}{r}\mathbf{4 5} \\
\mathbf{3 9} \\
\mathbf{4 1} \\
\mathbf{1 1} \\
\mathbf{3 1} \\
\mathbf{5 1} \\
\mathbf{3 9} \\
\mathbf{3 2} \\
\mathbf{2 8 9}\end{array}$ & $\begin{array}{r}30 \\
49 \\
17 \\
1 \\
17 \\
36 \\
34 \\
44 \\
228\end{array}$ & $\begin{array}{r}9 \\
\mathbf{9 0} \\
\mathbf{9} \\
\mathbf{2} \\
\mathbf{6} \\
7 \\
9 \\
6 \\
\mathbf{5 8}\end{array}$ & $\begin{array}{r}5 \\
11 \\
1 \\
0 \\
4 \\
10 \\
6 \\
12 \\
49\end{array}$ & $\begin{array}{r}12 \\
34 \\
50 \\
40 \\
47 \\
338\end{array}$ & $\begin{array}{r}42 \\
55 \\
28 \\
5 \\
26 \\
32 \\
40 \\
40 \\
268\end{array}$ \\
\hline vera & e 201 & $\begin{array}{l}181 \cdot 4 \\
84\end{array}$ & & $43 \cdot 1$ & & $2^{28 \cdot 5}$ & & 6. & & \\
\hline
\end{tabular}

Seven of the eight subjects wrote less under marijuana than in the control condition. On the binomial test for one-sample cases this effect is significant at the 0.035 level. The difference between the total scores for two conditions, however, was not significant. When only the content words are considered, not only do the subjects perform worse under the influence of marijuana $(P=0 \cdot 035)$. but the number of recalled content words is also significantly less in this condition $(P<0.005)$. The means were 56.9 and 43.1 for control and marijuana conditions respectively. The difference was evaluated by the $t$ test for correlated means?.

With the two word sequences, only six subjects did worse under marijuana than in the control condition. This effect was not significant. When the total number of two word sequences in the two conditions is considered, however, the difference between the two means (36.1 and 28.5 for control and marijuana conditions respectively) is significant at above the 0.025 level.

The final index was the number of idea units in the recalls. Once again, subjects under marijuana tended to do worse but the trend was not significant. The means for the marijuana and the control conditions were 42.3 and 33.5 respectively $(P<0.01)$, indicating that when there was an effect, it was significant.

The result of being "high" in this experiment was that subjects were not as capable of reproducing material which they had recently read. Not only were subjects worse at recalling exact words, they were also worse at recalling the ideas of the story they had just read. It is also noteworthy that the degree of impairment is significant. One can thus expect more than minor differences in behaviour as a result of smoking marijuana. The nature and direction of these differences await further study. But although individuals did do worse under marijuana, they were still able to read, remember and. write when they needed to. 